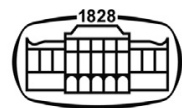

AKADÉMIAI KIADÓ

Acta Chromatographica

33 (2021) 2, 170-178

DOI:

$10.1556 / 1326.2020 .00690$

(c) 2020 The Authors

\section{ORIGINAL RESEARCH} PAPER

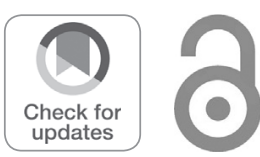

\title{
Exploiting column chemistry for chromatographic separation and quantification of caffeoylquinic acids in Gynura procumbens
}

\author{
KISANTINI MURUGESU ${ }^{1}$, SULTAN AYESH \\ MOHAMMED SAGHIR ${ }^{2,3}$, AMIRIN SADIKUN ${ }^{1}$, \\ KOOI-YEONG KHAW ${ }^{4}$ and \\ VIKNESWARAN MURUGAIYAH ${ }^{2 *}$ (])
}

${ }^{1}$ Discipline of Pharmaceutical Chemistry, School of Pharmaceuticual Sciences, Universiti Sains Malaysia, 11800 Penang, Malaysia

${ }^{2}$ Discipline of Pharmacology, School of Pharmaceutical Sciences, Universiti Sains Malaysia, 11800 Penang, Malaysia

${ }^{3}$ Department of Medical Analysis, Princess Aisha Bint Al-Hussein College of Nursing and Medical Sciences, Al-Hussein Bin Talal University, Ma'an, Jordan

${ }^{4}$ School of Pharmacy, Monash University Malaysia, Jalan Lagoon Selatan, Bandar Sunway, Subang Jaya, Selangor, 47500, Malaysia

Received: August 11, 2019 • Accepted: May 4, 2020

Published online: July 17, 2020

\begin{abstract}
A simple and sensitive high-performance liquid chromatography-ultraviolet (HPLC-UV) method was developed by exploiting the benefits of phenyl-hexyl column for the simultaneous determination of monoand di-caffeoylquinic acids in Gynura procumbens plant samples. An optimal chromatographic separation was achieved by using a mobile phase of acetonitrile: $0.25 \%$ acetic acid in water $(12.5: 78.5, \mathrm{v} / \mathrm{v})$ and detection at $330 \mathrm{~nm}$. The limits of detection (LOD) and quantification (LOQ) for the six caffeoylquinic acid standards were in the range of $0.078-0.653$ and $0.259-1.795 \mu \mathrm{g} / \mathrm{mL}$, respectively. The accuracies of the developed method were in the range of $96.84-103.08 \%$, while the corresponding precisions were between 0 and $2.94 \%$ for both within-day and between-day analyses, indicating that the method is repeatable and reliable. The mean recoveries were between 87.08 and $117.83 \%$. The method was successfully applied for quantification of caffeoylquinic acids in G. procumbens plant samples. This is the first study on di-caffeoylquinic acids quantification in G. procumbens. Leaves samples contained higher amount of the caffeoylquinic acids compared to stem samples. Of the compounds, 3,5-dicaffeoylquinic acid was found to be the major compound in almost all G. procumbens samples. The method has advantages such as sensitive ultraviolet (UV) detection, short run time with simple isocratic elution system compared to other methods which involved the use of costly instruments, laborious procedures with long run time and complex gradient system. This method can be further extended for routine quality control and analysis of plants or herbal products containing the caffeoylquinic acids.
\end{abstract}

\section{KEYWORDS}

mono-caffeoylquinic acid, di-caffeoylquinic acids, HPLC-UV detection, phenyl-hexyl column, Gynura procumbens

*Corresponding author. Discipline of Pharmacology, School of

Pharmaceutical Sciences, Universiti Sains Malaysia, 11800 Penang, Malaysia. Tel.: +60 4534583; fax: $+6046570017$

E-mail: vicky@usm.my

\section{INTRODUCTION}

The advancement of analytical techniques for simultaneous detection and quantification of phytochemicals in herbal preparations is always of great interest for the herbal or pharmaceutical industries. In the recent years, an increase in the development of herbal products has been observed and standardization of these products is an essential step to maintain the quality control during manufacturing [1]. In general, analyses of phytochemicals are carried 


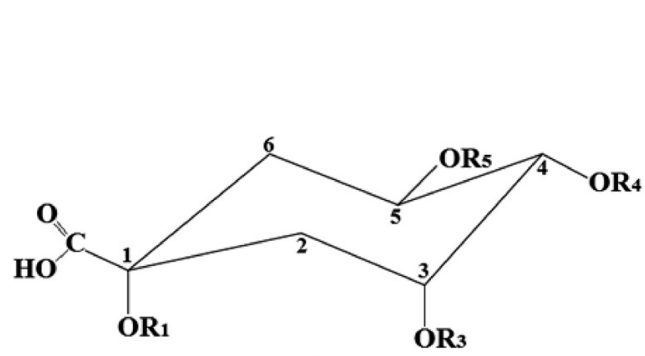

[Q]

\begin{tabular}{|l|c|c|c|c|}
\hline Name \& Abbreviation & $\mathbf{R}_{\mathbf{l}}$ & $\mathbf{R}_{\mathbf{3}}$ & $\mathbf{R}_{\mathbf{4}}$ & $\mathbf{R}_{\mathbf{5}}$ \\
\hline Chlorogenic acid (1) & $\mathrm{H}$ & $\mathrm{H}$ & $\mathrm{H}$ & $\mathrm{C}$ \\
\hline 3,4-dicaffeoylquinic acid(2) & $\mathrm{H}$ & $\mathrm{C}$ & $\mathrm{C}$ & $\mathrm{H}$ \\
\hline 3,5-dicaffeoylquinic acid (3) & $\mathrm{H}$ & $\mathrm{C}$ & $\mathrm{H}$ & $\mathrm{C}$ \\
\hline 4,5-dicaffeoylquinic acid(4) & $\mathrm{H}$ & $\mathrm{H}$ & $\mathrm{C}$ & $\mathrm{C}$ \\
\hline 1,3-dicaffeoylquinic acid (5) & $\mathrm{C}$ & $\mathrm{C}$ & $\mathrm{H}$ & $\mathrm{H}$ \\
\hline 1,5-dicaffeoylquinic acid (6) & $\mathrm{C}$ & $\mathrm{H}$ & $\mathrm{H}$ & $\mathrm{C}$ \\
\hline
\end{tabular}

$\mathrm{Q}=$ Quinic acid $\mathbf{C}=$ Caffeic acid

Fig. 1. Chemical structures of the mono- and di-caffeoylquinic acids.

out using different chromatography techniques such as high-performance liquid chromatography (HPLC), highperformance thin-layer chromatography (HPTLC), and gas chromatography (GC). Different detection methods have been used along with chromatographic techniques such as ultraviolet (UV) and mass spectrometry (MS).

For the past decade, much attention has been focused on phenolic acids including mono- and di-caffeoylquinic acids due to their extended range of pharmacological activities and several papers have been published on the identification of these compounds from different plants [2, 3]. Studies have revealed that di-caffeoylquinic acids such as 1,3dicaffeoylquinic acid (1,3DC), 1,5-dicaffeoylquinic acid (1,5DC), 3,4-dicaffeoylquinic acid (3,4DC), 3,5-dicaffeoylquinic acid (3,5DC) and 4,5-dicaffeoylquinic acid (4,5DC) possessed better antioxidant potential and protective role against cardiovascular diseases than the mono-caffeoylquinic acids. Besides their known radical scavenging activity, these compounds have been reported for many other biological properties such as antimicrobial, anti-inflammatory, hepatoprotective, neuroprotective, and anticancer [4-8], making any plants housing these compounds an excellent source of herbal medicine. In view of the impact of the caffeoylquinic acids on human health, it is very crucial to determine their contents in plants. Simultaneous identification of caffeoylquinic acids in plants is a complex task yet a number of methods have been published on the qualitative and quantitative analysis of these constituents [9]. A number of analytical methods have been described for the determination of caffeoylquinic acids in plant matrices using HPLCUV, HPLC-diode array detector (DAD) GCMS, LCMS and LC-NMR [2, 3, 8, 10-12].

Our preliminary studies on a local plant, Gynura procumbens revealed that it contains a number of phenolic acids that may be in part responsible for its pharmacological effect. The plant is non-toxic and the leaves are being used as a food source by the natives where it is generally consumed raw as salad [13]. Several studies have reported that the leaves of $G$. procumbens possess a vast range of activities such as antioxidant, antihyperglycemic, anti-inflammatory, antiulcer, anticancer and antihypertensive [14, 15]. Chemical constituents isolated from G. procumbens leaves include flavonoids, phenolic acids, tannins, terpenoids, saponins, alkaloids, coumarins and anthocyanins [14]. Although the biological properties of $G$. procumbens have been studied extensively, less is known about its phytochemicals. To the best of our knowledge, HPLC and HPTLC instruments have been utilized for the determination of several phenolic compounds (flavonoids and chlorogenic acid, CA) in G. procumbens but, no method has so far been reported for the determination of di-caffeoylquinic acids contents in G. procumbens [15]. Therefore, the present study is designed to develop a simple and sensitive method using HPLC-UV for the simultaneous identification and quantification of mono- and di-caffeoylquinic acids (Fig. 1) in G. procumbens plant samples.

\section{MATERIAL AND METHODS}

\section{Standards and solvents}

The following four standards: 1,3DC, 1,5DC, 3,4DC and 4,5DC, were purchased from Chengdu Biopurify Phytochemicals Ltd (Chengdu, China), while CA and 3,5DC were isolated in-house from $G$. procumbens. The purchased and isolated compounds had purity of more than $98 \%$ by HPLC. The HPLC grade acetonitrile (ACN) and methanol (MeOH) were purchased from J.T. Baker (China) while the analytical grade acetic acid glacial and formic acid $85 \%$ were supplied by QReC (Malaysia). Ethanol 95\% (EtOH) used for extraction was procured from Merck (Germany). Deionized water was prepared in-house.

\section{HPLC-UV method development}

The HPLC-UV method development was carried out using Agilent Technologies 1,200 Infinity Series liquid chromatography system (Agilent Technologies, USA) equipped with a quaternary solvent pump, an auto sampler, an UV-Vis detector and Chemstation data acquisition system. The HPLC analysis was carried out at room temperature $\left(25 \pm 2{ }^{\circ} \mathrm{C}\right)$. The sample injection volume used was $10 \mu \mathrm{L}$. The temperature of the columns was maintained at $30 \pm 2{ }^{\circ} \mathrm{C}$ and UV-Vis detector was operated at $330 \mathrm{~nm}$. All mobile phases were filtered using $0.45 \mu \mathrm{m}$ PTFE membrane filter (Fisher Scientific, USA) prior to use. In search of optimum chromatographic conditions for separation of monoand di-caffeoylquinic acids, different columns, mobile phase compositions, flow rates, and modifying agents were investigated to obtain good separation and peak resolution with reasonable run time (Table 1). Marker compounds used in the method development of G. procumbens plant samples were $\mathrm{CA}, 1,3 \mathrm{DC}, 1,5 \mathrm{DC}, 3,4 \mathrm{DC}, 3,5 \mathrm{DC}$ and $4,5 \mathrm{DC}$. The marker compounds were mixed to obtain mixed standards, which was used for method development. The best method 
Table 1. Parameters investigated in HPLC method development

\begin{tabular}{|c|c|}
\hline \multicolumn{2}{|l|}{ Parameters } \\
\hline Columns & $\begin{array}{c}\text { LiChroCART RP-18 }(250 \times 4.6 \mathrm{~mm} \text {, } \\
5 \mu \mathrm{m} \text { particle size, Merck, Germany }) \\
\text { SeQuant ZIC-HILIC }(150 \times 4.6 \mathrm{~mm} \text {, } \\
5 \mu \mathrm{m} \text { particle size, Merck, Germany }) \\
\text { Chromolith High Resolution RP-18 } \\
(100 \times 4.6 \mathrm{~mm}, 2 \mu \mathrm{m} \text { macropore size } \\
\text { and } 13 \mathrm{~nm} \text { mesopore size, Merck, } \\
\text { Germany) } \\
\text { ZORBAX Eclipse Plus phenyl-hexyl } \\
(250 \times 4.6 \mathrm{~mm}, 5 \mu \mathrm{m} \text { particle size, } \\
\text { Agilent Technologies, USA })\end{array}$ \\
\hline $\begin{array}{l}\text { Mobile phase } \\
\text { compositions }\end{array}$ & $\begin{array}{l}0.25 \% \text { Acetic acid in water (AAW): } \\
\text { ACN } \\
0.25 \% \text { Formic acid in water (FAW): } \\
\text { ACN }\end{array}$ \\
\hline Flow rate & $\begin{array}{l}1.0 \mathrm{~mL} / \mathrm{min} \\
0.8 \mathrm{~mL} / \mathrm{min}\end{array}$ \\
\hline Modifying agents & $\begin{array}{l}\text { Acetic acid } \\
\text { Formic acid }\end{array}$ \\
\hline
\end{tabular}

was subjected to determination of linearity range, limit of detection, limit of quantification and validation.

Linearity, Limit of Detection (LOD) and Limit of Quantification (LOQ). The mixed standard stock solution of CA, 1,3DC, 1,5DC, 3,4DC, 3,5DC and 4,5DC (each at 1,000 $\mu \mathrm{g}$ / $\mathrm{mL}$ ) was prepared in HPLC grade $\mathrm{MeOH}$, filtered through $0.45 \mu \mathrm{m}$ PTFE membrane filter and stored in the fridge $\left(4{ }^{\circ} \mathrm{C}\right)$ prior to use. Working standard solutions were freshly prepared from stock solution during the day of analysis. Serial dilutions of mixed standards in $\mathrm{MeOH}$ were injected into HPLC for determination of the limit of detection (LOD) and limit of Quantification (LOQ). The LOD and LOQ values were determined based on the standard deviation of the calibration curve and the slope of the regression line [16].

Method validation. From the stock solution, a series of working mixed standards solutions ranging from 1.565 to 25 $\mu \mathrm{g} / \mathrm{mL}$ were prepared by serial dilution with $\mathrm{MeOH}$ and were used to determine the precision, accuracy and recovery of the method. Separate calibration curves were generated on each day of analysis. The within-day analysis was carried out using working mixed standards solutions with five replicates each, all carried out in a single day, while the between-day analysis was carried out by injecting working mixed standards solutions once daily for five consecutive days. The accuracy values were expressed as percentage of true value while the corresponding precision values were expressed as relative standard deviation (RSD). The extraction recovery was carried out in triplicates by spiking the working standard solutions into powdered raw material. Raw materials of $100 \mathrm{mg}$ each were weighed accurately, spiked with three working mixed standards solutions, i.e.: low, medium and high concentrations $(25,6.25$ and $1.565 \mu \mathrm{g} / \mathrm{mL})$ and extracted by maceration using $95 \% \mathrm{EtOH}$ for 2 consecutive days on a heating water bath $\left(50^{\circ} \mathrm{C}\right)$. The extract was decanted, and fresh solvent was replenished daily. The extracts were then filtered using filter paper (Whatman No.1, England), pooled and concentrated under vacuo at $45^{\circ} \mathrm{C}$. The same quantity of raw materials, without spiking was also extracted as blank. The test samples were reconstituted and diluted accordingly with HPLC grade $\mathrm{MeOH}$ to final concentration of $1,000 \mu \mathrm{g} / \mathrm{mL}$ prior to analysis. The recovery value for each standard compound was calculated as the amount of standard compound recovered after extraction over initial amount before extraction.

\section{Quantification of mono- and di-caffeoylquinic acids in G. procumbens samples}

Preparation of G. procumbens test samples. To demonstrate the application of the newly developed method, it was applied to quantify the content of the mono- and di-caffeoylquinic acids in (i) $95 \%$ ethanol extracts of G. procumbens leaves and stems collected from various geographical locations and (ii) different aqueous ethanolic extracts of $G$. procumbens leaves.

For the first part of the method application, samples comprising of fresh leaves and stems were obtained from five different states in Malaysia [Perak $\left(4.1116^{\circ} \mathrm{N}\right.$, $\left.101.2878^{\circ} \mathrm{E}\right)$, Perlis $\left(6.4406^{\circ} \mathrm{N}, 100.1984^{\circ} \mathrm{E}\right)$, Terengganu $\left(5.4243^{\circ} \mathrm{N}, 103.0567^{\circ} \mathrm{E}\right)$, Melaka $\left(2.1452^{\circ} \mathrm{N}, 102.4224^{\circ} \mathrm{E}\right)$ and Penang $\left.\left(5.1474^{\circ} \mathrm{N}, 100.4212^{\circ} \mathrm{E}\right)\right]$. The dried and powdered raw materials were weighed accurately; $10 \mathrm{~g}$ for leaves and $6 \mathrm{~g}$ for stems and extracted by maceration using 95\% EtOH following the protocol described above in the validation section. The $95 \% \mathrm{EtOH}$ was chosen based on previous findings that suggest the content of phenolic acids were higher in extracting solvent containing least amount of water such as $95 \% \mathrm{EtOH}$ [17]. The $95 \% \mathrm{EtOH}$ solvent is a commonly used extraction solvent in phytochemical analysis of plant materials. Furthermore, the extract can be evaporated quickly and not easily contaminated with bacterial or fungal growth compared to aqueous solution.

The second part of the method application was carried out on different aqueous ethanolic extracts of G. procumbens leaves to determine which solvent system is the most ideal to extract highest amount of mono- and di-caffeoylquinic acid from $G$. procumbens leaves (since leaves has higher amount of these compounds compared to stem). The leaves of $G$. procumbens were purchased from Herbagus Sdn. Bhd (Kepala Batas, Malaysia). The fresh leaves were thoroughly washed with tap water, dried in oven at $45{ }^{\circ} \mathrm{C}$ and milled into fine powder. The extraction process was done using maceration method as described earlier, whereby $20 \mathrm{~g}$ raw material each were extracted in $95,75,50,25 \% \mathrm{v} / \mathrm{v}$ ethanolic aqueous and $100 \%$ water (powder:solvent ratio of 1:10). The extracts were then pooled and concentrated under vacuo at $45{ }^{\circ} \mathrm{C}$ to afford $1.62 \mathrm{~g}$ (8.10\%), $3.31 \mathrm{~g}$ (16.55\%), $4.51 \mathrm{~g}$ (22.55\%), $6.26 \mathrm{~g}(31.30 \%)$ and $8.51 \mathrm{~g}(42.55 \%)$, of dried extract of $95,75,50,25 \%$ ethanolic aqueous extracts and 


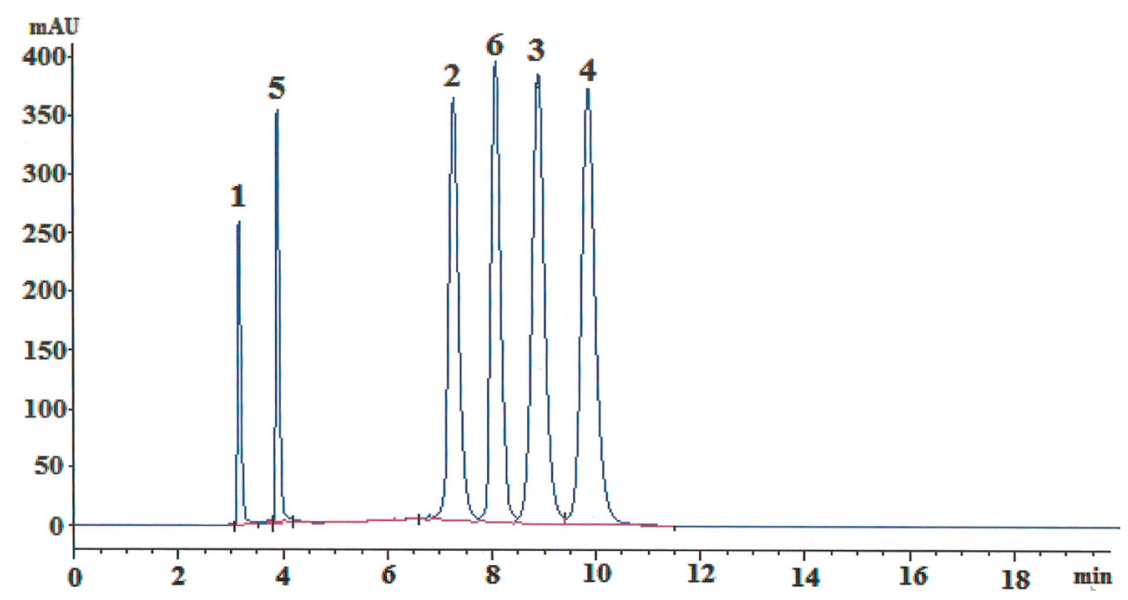

Fig. 2. Chromatogram of mixed standards. Operating conditions: (a) column: ZORBAX Eclipse Plus phenyl-hexyl column $(250 \times 4.6 \mathrm{~mm}$, 5 $\mu \mathrm{m})(\mathrm{b})$ mobile phase consisting of ACN: 0.25\% AAW (21.5:78.5 v/v) run in isocratic mode (c) UV detection wavelength $330 \mathrm{~nm}(\mathrm{~d})$ flow rate $1.0 \mathrm{~mL} / \mathrm{min}$. Peaks are in order: (1) CA; (2) 3,4DC; (3) 3,5DC; (4) 4,5DC (5) 1,3DC; (6) 1,5DC.

aqueous extract, respectively. Dried extracts were freeze dried and kept in the fridge $\left(4^{\circ} \mathrm{C}\right)$ prior to analysis.

Chromatography conditions. HPLC-UV analysis was conducted using the newly developed method on Agilent Technologies 1,200 Infinity Series liquid chromatography system (Agilent Technologies, USA) equipped with a quaternary solvent pump, an UV-Vis detector and Chemstation data acquisition system. Separation was done on ZORBAX Eclipse Plus phenyl-hexyl column $(250 \times 4.6 \mathrm{~mm}, 5 \mu \mathrm{m})$. The mobile phase consists of ACN: 0.25\% AAW (12.5:78.5 $\mathrm{v} / \mathrm{v})$ at a flow rate of $1.0 \mathrm{~mL} / \mathrm{min}$. The sample injection volume used was $10 \mu \mathrm{L}$ and UV detector was operated at 330 $\mathrm{nm}$. The temperature of the column was maintained at $30 \pm$ $2{ }^{\circ} \mathrm{C}$. All freeze-dried samples of $G$. procumbens extracts were accurately weighed and dissolved in HPLC grade $\mathrm{MeOH}$ to a concentration of $1,000 \mu \mathrm{g} / \mathrm{mL}$. The samples were diluted accordingly with HPLC grade $\mathrm{MeOH}$ and filtered through PTFE membrane filter $0.45 \mu \mathrm{m}$ prior to injection. The peaks in the samples chromatograms were identified by comparing with the retention times of standards. Calibration curves were generated for all standards prior to analysis and quantification was done with respect to the calibration curve of the standards.

\section{RESULTS AND DISCUSSION}

HPLC-UV analysis has been widely employed in pharmaceutical and herbal industries for quality control, fingerprinting and quantification of phytochemicals in plant samples or plant-based products. Despite the complexity of plant materials, HPLC-UV offers an economical, feasible, relatively sensitive and reliable analytical tool that is sufficient for routine analyses of phytochemicals. In the present study, a HPLC-UV method was developed for separation and quantification of the phenolic acids, namely the monoand di-caffeoylquinic acids (CA; 1,3DC; 1,5DC; 3,4DC; $3,5 \mathrm{DC} ; 4,5 \mathrm{DC})$ in the G. procumbens plant. The method development was carried out on four columns of different polarity and optimized according to column chemistry, solvent strength and flow rate to achieve the best chromatographic separation of the six compounds (Table 1).

The suitable wavelength for the simultaneous determination of phenolic acids was determined based on UV scan in the range of $200-400 \mathrm{~nm}$. The $\lambda$ maximum of $330 \mathrm{~nm}$ was selected for HPLC-UV analysis. Isocratic mobile phase system consisting of ACN and water was employed based on previous phenolic compounds analyses that suggest $\mathrm{ACN}$ : water as a better solvent system compared to $\mathrm{MeOH}$ : water, as the former will result in a better resolution and peak shape compared to latter [18-20]. The former system is usually less viscous and provides lower background absorbance at low wavelengths compared to any other solvents such as $\mathrm{MeOH}$, tetrahydrofuran or isopropanol [18, 21]. In addition, acetic acid or formic acid was used as modifier in the mobile phase to prevent deprotonation of compounds resulting in peak tailing and broadening $[20,22]$. The mobile phase composition was varied for each column to achieve separation with good peak resolution and reasonable run time.

LiChroCART RP-18 column, made of highly purified silica was employed due to its ability to prevent silanophilic interactions. Compared to conventional columns, the absence of metals in silica matrix in this column provides an excellent separation with good peak symmetry by preventing tailing of compounds. Use of LiChroCART RP-18 column at mobile phase condition of ACN: $0.25 \%$ acetic acid water, $\operatorname{AAW}(22: 78 \mathrm{v} / \mathrm{v})$ at a flow rate of $1 \mathrm{~mL} / \mathrm{min}$ resulted in total run time of less than $20 \mathrm{~min}$ but co-elution of 3,4DC and $3,5 \mathrm{DC}$. Further increase in the proportion of AAW up to $85 \%$ still resulted in co-elution of those compounds and increased the total run time to $90 \mathrm{~min}$ (Fig. 1S). Further attempts of separation were made using Chromolith RP-18. Unlike normal silica columns, Chromolith RP-18 columns consist of unique packing materials that give improved chromatographic performance in terms of separation and column back pressure. Existence of macropores $(2 \mu \mathrm{m})$ 
Table 2. Calibration results, LOD and LOQ of the caffeoylquinic acids

\begin{tabular}{lcccccc}
\hline Analyte & Retention time $(\mathrm{min})$ & LOD $(\mu \mathrm{g} / \mathrm{mL})$ & LOQ $(\mu \mathrm{g} / \mathrm{mL})$ & Linear range $(\mu \mathrm{g} / \mathrm{mL})$ & Calibration curve & $r^{2}$ \\
\hline CA & 3.16 & 0.653 & 2.177 & $1.565-25$ & $\mathrm{y}=2.661 \mathrm{x}-0.602$ & 0.999 \\
$1,3 \mathrm{DC}$ & 3.85 & 0.157 & 0.424 & $1.565-25$ & $\mathrm{y}=1.529 \mathrm{x}-0.149$ & 0.999 \\
$1,5 \mathrm{DC}$ & 8.03 & 0.218 & 0.789 & $1.565-25$ & $\mathrm{y}=1.636 \mathrm{x}-0.103$ & 0.999 \\
$3,4 \mathrm{DC}$ & 7.26 & 0.401 & 1.338 & $1.565-25$ & $\mathrm{y}=0.882 \mathrm{x}-0.192$ & 0.999 \\
3,5DC & 8.88 & 0.538 & 1.795 & $1.565-25$ & $\mathrm{y}=0.754 \mathrm{x}-0.409$ & 0.999 \\
$4,5 \mathrm{DC}$ & 9.83 & 0.078 & 0.259 & $1.565-25$ & $\mathrm{y}=1.068 \mathrm{x}+0.207$ & 0.999 \\
\hline
\end{tabular}

allows rapid flow of mobile phases and reduces column back pressure therefore reduces analysis time, while mesopores $(13 \mathrm{~nm})$ with fine porous structures provide large surface area for highly efficient separation. A mobile phase condition of $80 \%$ AAW: $20 \% \mathrm{ACN}$, run at a flow rate of $1 \mathrm{~mL} / \mathrm{min}$ resulted in elution of all compounds within 5 min but poorly separated and overlapping peaks. Further increase of mobile phase composition up to $86 \%$ of AAW resulted in co-elution of 3,4DC and 1,5DC. A mobile phase composition of $90 \%$ AAW resulted in clustered, broad and unsymmetrical peak (Fig. 2S).

Subsequent attempt was made using ZIC-HILIC column, which is specially developed for the separation of hydrophilic and polar compounds in HILIC mode (hydrophilic interaction liquid chromatography). The column is made up of zwitterionic stationary phase consisting of highly polar sulphobetaine structure which makes the column overall neutral with important ionic interactions. Mobile phase of $80 \%$ AAW: $20 \% \mathrm{ACN}$ at a flow rate of $1 \mathrm{~mL} / \mathrm{min}$ resulted in co-elution of all the compounds though the run time was less than $5 \mathrm{~min}$. Gradual increase the polarity of the mobile phase gave a better separation at mobile phase of 88\% AAW: $12 \%$ ACN except for CA and 1,3DC. However, further increase in proportion of AAW up to $94 \%$ resulted in not much improvement but co-elution of 3,5DC and 4,5DC (Fig. 3S). Adjustment of flow rate between $0.8 \mathrm{~mL} / \mathrm{min}$ and

Table 3. Recovery, within-day and between-day precision and accuracy values of the caffeoylquinic acids

\begin{tabular}{|c|c|c|c|c|c|c|c|}
\hline \multirow[b]{2}{*}{ Analyte } & \multirow[b]{2}{*}{$\begin{array}{l}\text { Concentration } \\
\qquad(\mu \mathrm{g} / \mathrm{mL})\end{array}$} & \multicolumn{2}{|c|}{ Recovery $(n=3)$} & \multicolumn{2}{|r|}{ Within-day $(n=5)$} & \multicolumn{2}{|c|}{ Between-day $(n=5)$} \\
\hline & & Mean (\%) & RSD (\%) & Accuracy (\%) & Precision RSD (\%) & Accuracy (\%) & $\begin{array}{l}\text { Precision } \\
\text { RSD (\%) }\end{array}$ \\
\hline \multirow[t]{5}{*}{$\mathrm{CA}$} & 25 & 87.08 & 1.74 & 100.57 & 0.30 & 100.75 & 0.52 \\
\hline & 12.5 & - & - & 97.87 & 0.50 & 97.36 & 0.77 \\
\hline & 6.25 & 106.02 & 1.93 & 99.33 & 0.71 & 98.24 & 1.91 \\
\hline & 3.125 & - & - & 101.74 & 1.39 & 99.77 & 2.78 \\
\hline & 1.565 & 104.85 & 2.40 & 99.92 & 1.15 & 99.31 & 1.72 \\
\hline \multirow[t]{5}{*}{$1,3 \mathrm{DC}$} & 25 & 98.43 & 1.67 & 97.62 & 0.27 & 104.56 & 1.03 \\
\hline & 12.5 & - & - & 99.31 & 1.75 & 98.12 & 0.66 \\
\hline & 6.25 & 94.61 & 0.87 & 103.75 & 0.94 & 99.73 & 1.54 \\
\hline & 3.125 & - & - & 100.62 & 0.32 & 102.28 & 1.11 \\
\hline & 1.565 & 100.25 & 0.55 & 103.08 & 2.43 & 96.84 & 2.13 \\
\hline \multirow[t]{5}{*}{$1,5 \mathrm{DC}$} & 25 & 105.67 & 0.24 & 100.71 & 1.43 & 98.91 & 1.01 \\
\hline & 12.5 & - & - & 102.13 & 0.90 & 100.44 & 1.49 \\
\hline & 6.25 & 109.10 & 1.45 & 99.88 & 0.88 & 98.54 & 0.71 \\
\hline & 3.125 & - & - & 104.80 & 2.27 & 99.02 & 2.40 \\
\hline & 1.565 & 110.22 & 1.05 & 97.20 & 1.84 & 102.29 & 2.21 \\
\hline \multirow[t]{5}{*}{$3,4 \mathrm{DC}$} & 25 & 117.83 & 2.62 & 100.89 & 1.34 & 100.72 & 0.98 \\
\hline & 12.5 & - & - & 101.02 & 1.00 & 101.00 & 1.30 \\
\hline & 6.25 & 96.41 & 0.00 & 101.39 & 1.27 & 101.30 & 2.11 \\
\hline & 3.125 & - & - & 99.88 & 0.00 & 100.37 & 1.64 \\
\hline & 1.565 & 103.45 & 0.84 & 97.60 & 2.53 & 97.91 & 1.29 \\
\hline \multirow[t]{5}{*}{$3,5 \mathrm{DC}$} & 25 & 110.70 & 1.84 & 100.76 & 0.53 & 100.40 & 0.44 \\
\hline & 12.5 & - & - & 97.52 & 1.49 & 97.89 & 1.32 \\
\hline & 6.25 & 100.44 & 2.45 & 97.34 & 1.37 & 97.18 & 1.73 \\
\hline & 3.125 & - & - & 98.63 & 2.94 & 99.42 & 1.89 \\
\hline & 1.565 & 97.46 & 2.45 & 99.39 & 1.84 & 98.01 & 2.87 \\
\hline \multirow[t]{5}{*}{$4,5 \mathrm{DC}$} & 25 & 112.92 & 1.89 & 101.31 & 1.41 & 101.55 & 0.97 \\
\hline & 12.5 & - & - & 100.01 & 0.49 & 100.21 & 1.63 \\
\hline & 6.25 & 116.58 & 2.29 & 99.88 & 1.24 & 100.68 & 2.16 \\
\hline & 3.125 & - & - & 98.79 & 2.34 & 98.54 & 0.94 \\
\hline & 1.565 & 96.64 & 0 & 99.21 & 0.00 & 102.00 & 1.86 \\
\hline
\end{tabular}


Table 4. Content of caffeoylquinic acids in plant samples from different geographical locations and various aqueous ethanolic extracts of Gynura procumbens

\begin{tabular}{|c|c|c|c|c|c|c|c|c|c|}
\hline \multirow[b]{2}{*}{ Sample } & \multicolumn{5}{|c|}{$\begin{array}{c}\text { Content of caffeoylquinic } \\
\text { acids }(\mu \mathrm{g} / \mathrm{mg})\end{array}$} & \multicolumn{4}{|c|}{$\begin{array}{l}\text { Relative distribution of } \\
\text { caffeoylquinic acids }\end{array}$} \\
\hline & $3,4 \mathrm{DC}$ & $3,5 \mathrm{DC}$ & $4,5 \mathrm{DC}$ & CA & Total & $3,4 \mathrm{DC}$ & $3,5 \mathrm{DC}$ & $4,5 \mathrm{DC}$ & CA \\
\hline \multicolumn{10}{|c|}{ Leaves (95\% EtOH) } \\
\hline Perak & $4.83 \pm 0.19$ & $12.26 \pm 0.08$ & $3.74 \pm 0.49$ & $2.31 \pm 0.17$ & 23.13 & 0.39 & 1.00 & 0.31 & 0.19 \\
\hline Perlis & $9.44 \pm 0.28$ & $66.90 \pm 0.34$ & $14.16 \pm 0.03$ & $4.95 \pm 0.06$ & 95.45 & 0.14 & 1.00 & 0.21 & 0.07 \\
\hline Penang & $7.44 \pm 0.06$ & $6.60 \pm 0.09$ & $3.11 \pm 0.28$ & $4.61 \pm 0.02$ & 21.76 & 1.13 & 1.00 & 0.47 & 0.70 \\
\hline Melaka & $20.78 \pm 0.55$ & $46.61 \pm 0.11$ & $12.38 \pm 0.08$ & $7.54 \pm 0.38$ & 87.31 & 0.45 & 1.00 & 0.27 & 0.16 \\
\hline Terengganu & $0.76 \pm 0.30$ & $1.55 \pm 0.47$ & $0.16 \pm 0.36$ & $1.28 \pm 0.64$ & 3.75 & 0.49 & 1.00 & 0.10 & 0.82 \\
\hline \multicolumn{10}{|c|}{ Stem $(95 \%$ EtOH $)$} \\
\hline Perak & $0.74 \pm 0.43$ & $1.37 \pm 0.11$ & $0.17 \pm 0.09$ & $1.15 \pm 0.26$ & 3.43 & 0.54 & 1.00 & 0.12 & 0.84 \\
\hline Perlis & $2.83 \pm 0.56$ & $5.10 \pm 0.24$ & $1.87 \pm 0.14$ & $1.84 \pm 0.07$ & 11.63 & 0.55 & 1.00 & 0.37 & 0.36 \\
\hline Penang & $1.65 \pm 0.15$ & $2.71 \pm 0.28$ & $1.02 \pm 0.33$ & $1.77 \pm 0.36$ & 7.15 & 0.61 & 1.00 & 0.38 & 0.65 \\
\hline Melaka & $1.43 \pm 0.03$ & $4.30 \pm 0.42$ & $1.18 \pm 0.35$ & $2.28 \pm 0.05$ & 9.19 & 0.33 & 1.00 & 0.27 & 0.53 \\
\hline Terengganu & $1.30 \pm 0.01$ & $2.62 \pm 0.06$ & $0.66 \pm 0.55$ & $1.40 \pm 0.02$ & 5.99 & 0.50 & 1.00 & 0.25 & 0.54 \\
\hline \multicolumn{10}{|c|}{ Aqueous ethanolic extracts of leaves } \\
\hline $95 \% \mathrm{EtOH}$ & $1.65 \pm 0.09$ & $13.08 \pm 0.09$ & $3.06 \pm 0.14$ & $1.72 \pm 0.47$ & 19.51 & 0.13 & 1.00 & 0.23 & 0.13 \\
\hline $75 \% \mathrm{EtOH}$ & $2.54 \pm 0.11$ & $18.38 \pm 0.05$ & $5.03 \pm 0.44$ & $4.27 \pm 0.06$ & 30.21 & 0.14 & 1.00 & 0.27 & 0.23 \\
\hline $50 \% \mathrm{EtOH}$ & $2.46 \pm 0.23$ & $13.14 \pm 0.17$ & $2.92 \pm 0.35$ & $5.20 \pm 0.01$ & 23.71 & 0.19 & 1.00 & 0.22 & 0.40 \\
\hline $25 \% \mathrm{EtOH}$ & $0.67 \pm 0.36$ & $1.14 \pm 0.44$ & $0.13 \pm 0.13$ & $3.98 \pm 0.12$ & 5.92 & 0.59 & 1.00 & 0.12 & 3.51 \\
\hline Aqueous & ND & ND & ND & $2.07 \pm 0.05$ & 2.07 & - & - & - & - \\
\hline
\end{tabular}

$1.0 \mathrm{~mL} / \mathrm{min}$ as well as addition of other modifying agent (formic acid) did not result in good separation. Thus, incomplete separation and co-elution of compounds was observed with the use of LiChroCART RP-18, SeQuant ZICHILIC and Chromolith High Resolution RP-18. Next, ZORBAX Eclipse Plus phenyl-hexyl column was investigated for separation of the six compounds. Unlike the standard columns, phenyl-hexyl offers mixed mode characteristics which allow much greater separation of the aromatic compounds through its extended alkyl chain. The mobile phase compositions of AAW:ACN were ranged from 78:22 to $82: 18 \%$. The six compounds were separated with a total run time of less than $20 \mathrm{~min}$. The use of ZORBAX Eclipse Plus phenyl-hexyl column resulted in excellent separation of all six caffeoylquinic acids in terms of peak symmetry and resolution. The optimal chromatographic separation was achieved with mobile phase consisting of ACN: $0.25 \% \mathrm{AAW}(12.5: 78.5 \mathrm{v} / \mathrm{v})$ at a flow rate of $1.0 \mathrm{~mL} /$ min. The total run time was 12 min (Fig. 2).

Among all four columns, phenyl-hexyl column gave the best separation, hence the method was validated. Table 2 summarizes the calibration results, LOD and LOQ of all six caffeoylquinic acids standards. The linearity of the method was determined using five concentrations in the range of 25$1.565 \mu \mathrm{g} / \mathrm{mL}$. Calibration curves of the compounds, generated using peak height showed excellent linearity and correlation coefficients $\left(r^{2}=0.999\right)$ over the concentration range investigated. The LOD and LOQ values for the six compounds were in the range of $0.078-0.653$ and $0.259-$ $1.795 \mu \mathrm{g} / \mathrm{mL}$, respectively (Table 2). The validation data are summarized in Table 3. The recoveries of the six compounds ranged from 87.08 to $117.83 \%$, indicating satisfactory recovery and implying that the extraction technique used did not contribute to any appreciable loss of the compounds. The accuracies for the caffeoylquinic acids were in the range of $96.84-103.08 \%$, while the corresponding precisions were in between 0 and $2.94 \%$ for both within-day and betweenday analyses, indicating that the method is reliable and repeatable.

The developed method was successfully applied for the quantification of the caffeoylquinic acids in G. procumbens plant samples from different locations and in different aqueous ethanolic extracts of the leaves (Table 4). The chromatograms of the leaves (Fig. 3) and stems (Fig. 4) extracts of $G$. procumbens samples collected from five different states were comparable but vary in the caffeoylquinic acids content. Compounds CA, 3,4DC, 3,5DC and 4,5DC were present while $1,3 \mathrm{DC}$ and $1,5 \mathrm{DC}$ were absent in the G. procumbens plant samples. The compounds peak purity was determined using the same HPLC system but connected to a DAD detector operated at several wavelengths: $218,244,262$, 280 and $330 \mathrm{~nm}$. The purity was found to be more than 0.999 , indicating the compounds peaks are pure (Fig. 4S). The total contents of four caffeoylquinic acids were between 3.43 and $95.45 \mu \mathrm{g} / \mathrm{mg}$ of extract [1.15-7.54 $\mu \mathrm{g} / \mathrm{mg}$ of extract, $0.74-$ $20.78 \mu \mathrm{g} / \mathrm{mg}$ of extract, $1.37-66.90 \mu \mathrm{g} / \mathrm{mg}$ of extract and $0.16-$ $14.16 \mu \mathrm{g} / \mathrm{mg}$ of extract for compounds CA; 3,4DC; 3,5DC and $4,5 \mathrm{DC}$, respectively]. The results showed that leaves of $G$. procumbens contain more total caffeoylquinic content compared to stem. Among the samples, leaves and stems from Perlis have the highest total content of the four caffeoylquinic acids. Among the compounds, 3,5DC was found to be the most abundant in all samples except leaves from Penang. The variation between leaves and stems suggests that 


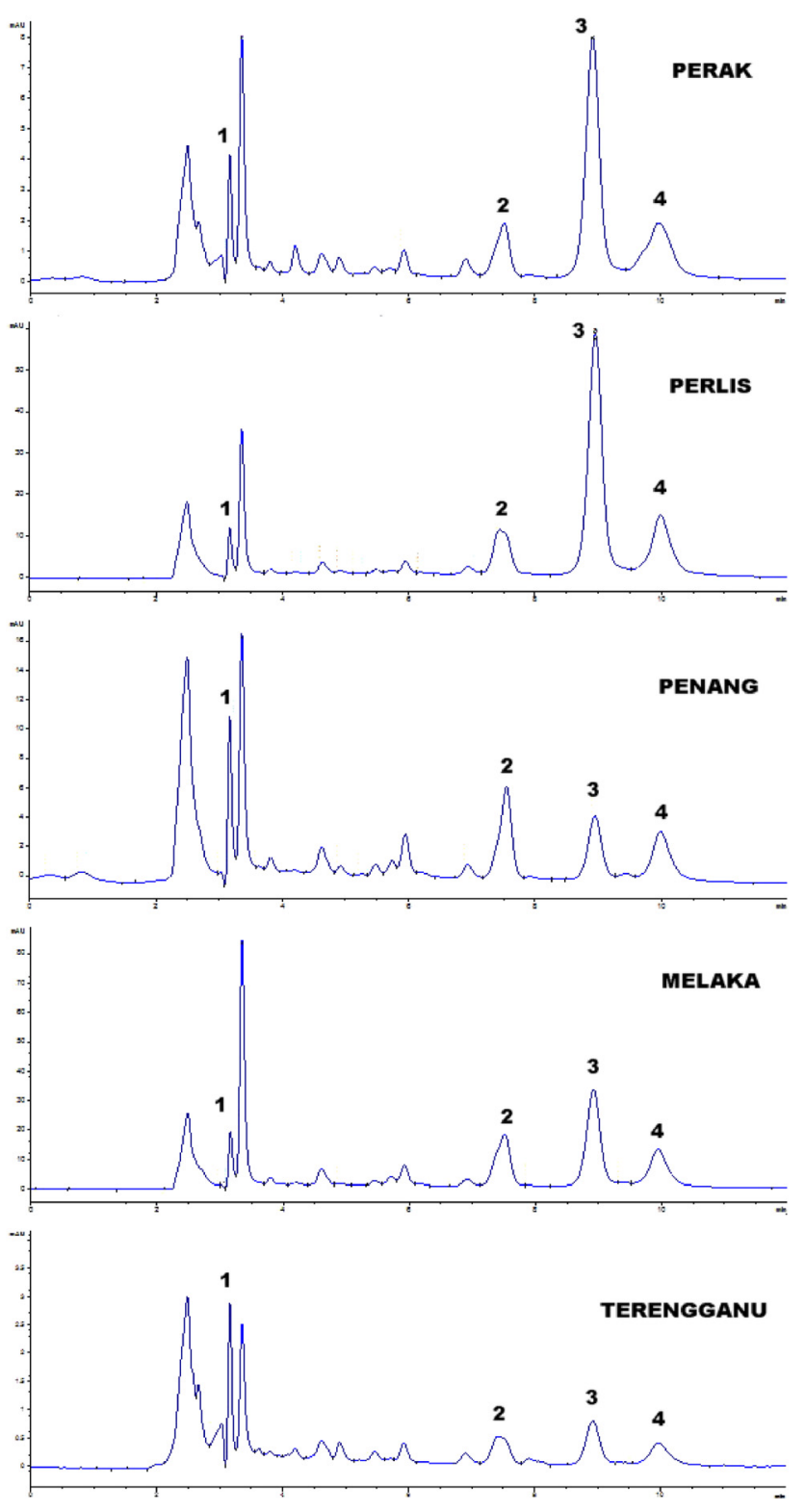

Fig. 3. Representative chromatograms of $95 \%$ ethanolic extracts of G. procumbens leaves collected from different geographical locations. Operating conditions: (a) column: ZORBAX Eclipse Plus phenyl-hexyl column $(250 \times 4.6 \mathrm{~mm}, 5 \mu \mathrm{m})(\mathrm{b})$ mobile phase consisting of ACN: $0.25 \%$ AAW $(21.5: 78.5 \mathrm{v} / \mathrm{v})$ run in isocratic mode (c) UV detection wavelength $330 \mathrm{~nm}$ (d) flow rate $1.0 \mathrm{~mL} / \mathrm{min}$. Peaks are in order: (1) CA; (2) 3,4DC; (3) 3,5DC; (4) 4,5DC.

the phenolic acids are more synthesized in leaves than stem [23]. The variability of phenolic acids content among plant samples from different geographical locations could be contributed to the following factors: growing conditions, altitude, maturity stage and sampling period [10, 19, 23, 24].

Fig. 5 shows chromatograms of various aqueous ethanolic extracts of $G$. procumbens. The extraction of polyphenols including phenolic acids is commonly carried out using polar solvents like water, $\mathrm{MeOH}$ and $\mathrm{EtOH}[3,25]$. However, to date there is no information on the ideal solvent system for optimal extraction of caffeoylquinic acids from $G$. procumbens, thus various aqueous ethanol combinations were investigated in this study for the caffeoylquinic acids content using the newly developed HPLC-UV method. It was found that $3,5 \mathrm{DC}$ is the major caffeoylquinic acid found in 95, 75 and 50\% ethanolic extracts while CA was the major caffeoylquinic acid found in $25 \%$ ethanolic extract and water extract. The total content of the four caffeoylquinic acids was highest in $75 \%$ ethanolic extract followed by 50 and $95 \%$ ethanolic extracts. The findings showed that the content of $\mathrm{CA}$ increases as the water content in the extracting solvent increases. CA consists of both polar carboxylic group and less polar phenolic group. Therefore the presence of water in the extraction solvent will increase the solubility of CA during the extraction process. However, further increase of water content to $75 \%$ and above decreased the solubility of CA which could be due to the less polar phenolic structure in CA $[26,27]$. Meanwhile, di-caffeoylquinic acids content were highest in $75 \%$ ethanolic extract and their content decreased with an increase of the water composition in the 

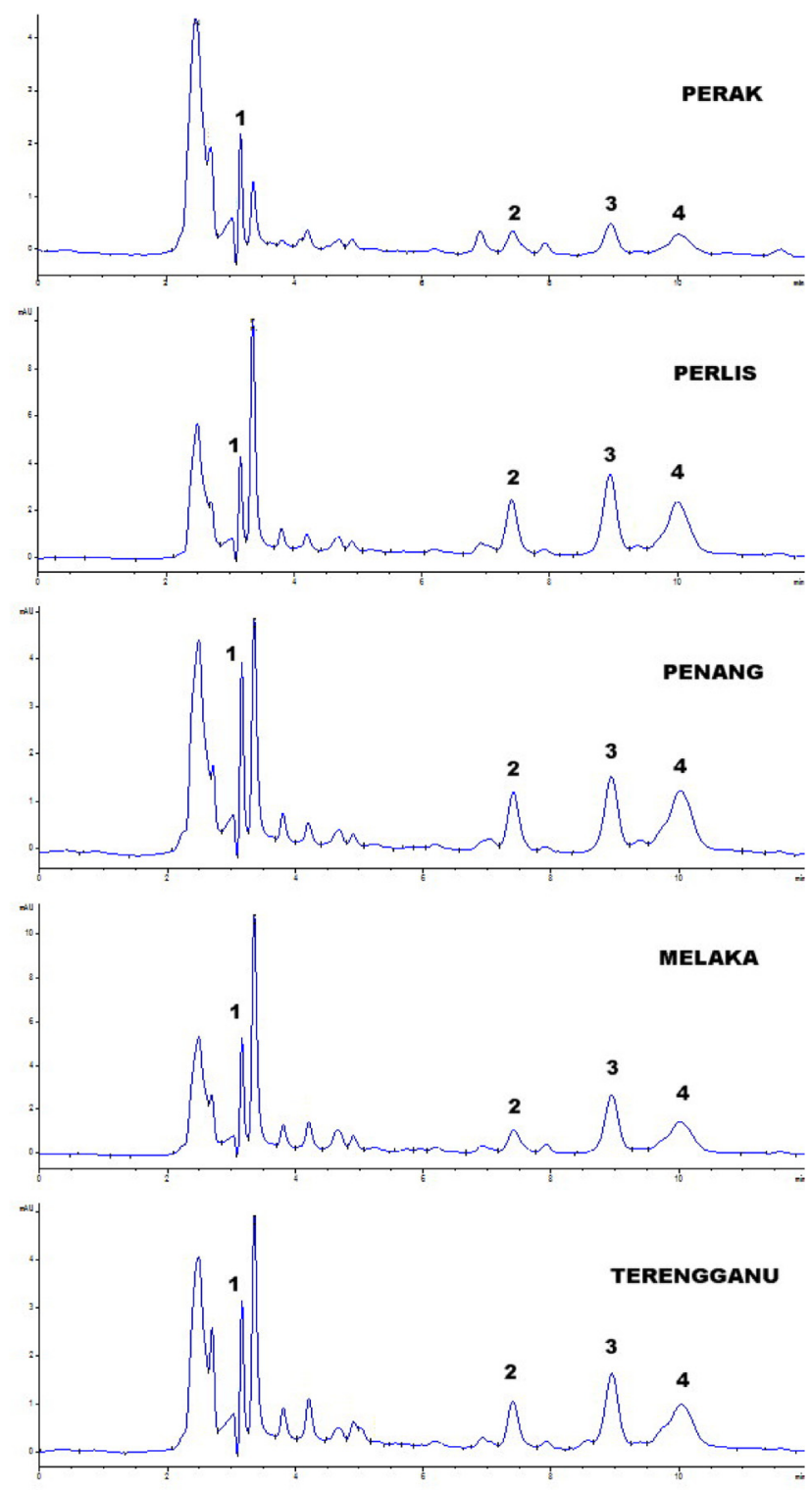

Fig. 4. Representative chromatograms of $95 \%$ ethanolic extracts of G. procumbens stems collected from different geographical locations. Operating conditions: (a) column: ZORBAX Eclipse Plus phenyl-hexyl column $(250 \times 4.6 \mathrm{~mm}, 5 \mu \mathrm{m})(\mathrm{b})$ mobile phase consisting of ACN: $0.25 \%$ AAW (21.5:78.5 v/v) run in isocratic mode (c) UV detection wavelength $330 \mathrm{~nm}$ (d) flow rate $1.0 \mathrm{~mL} /$ min. Peaks are in order: (1) CA; (2) 3,4DC; (3) 3,5DC; (4) 4,5DC.

extraction solvent. The structures of di-caffeoylquinic acids contains more phenolic groups which are less polar, thus very likely to be soluble in less polar solvent. It was mentioned that di-caffeoylquinic acids exhibit weaker polarity compared to CA which results in slower release of these compounds when extracted with water [28].

To date, the di-caffeoylquinic acids have not been reported in G. procumbens although they have been isolated from other Gynura species such as Gynura divaricata [23], Gynura bicolor [29] and Gynura pseudochina var. hispida [30]. To the best of our knowledge, this is the first study that identified and quantified the di-caffeoylquinic acids in $G$. procumbens. There are a number of studies concerning the

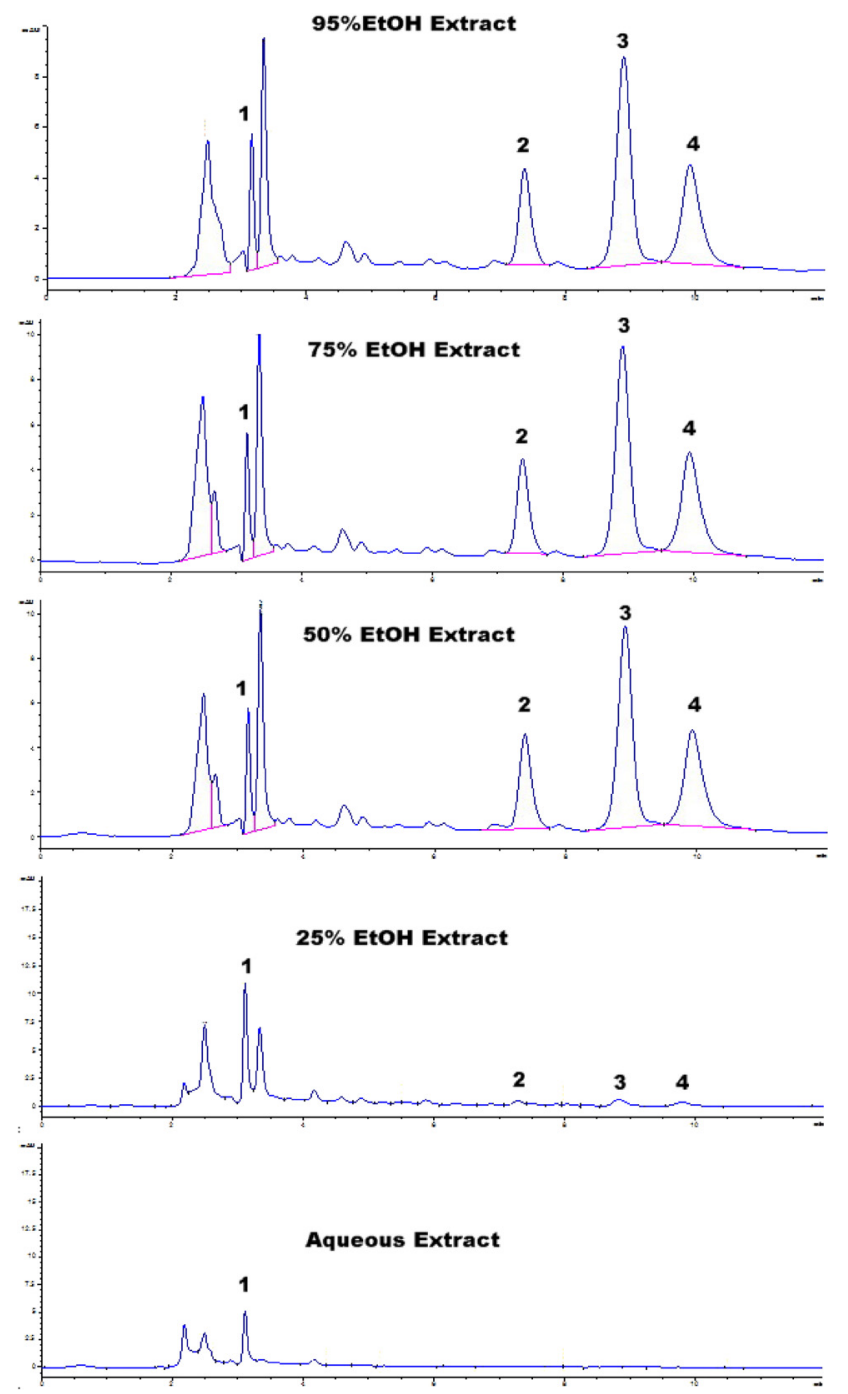

Fig. 5. Representative chromatograms of various ethanolic and aqueous extracts of $G$. procumbens leaves. Operating conditions: (a) column: ZORBAX Eclipse Plus phenyl-hexyl column $(250 \times 4.6$ $\mathrm{mm}, 5 \mu \mathrm{m})(\mathrm{b})$ mobile phase consisting of ACN: $0.25 \%$ AAW $(21.5: 78.5 \mathrm{v} / \mathrm{v})$ run in isocratic mode (c) UV detection wavelength $330 \mathrm{~nm}$ (d) flow rate $1.0 \mathrm{~mL} / \mathrm{min}$. Peaks are in order: (1) CA; (2) 3,4DC; (3) 3,5DC; (4) 4,5DC.

determination of $\mathrm{CA}$ and di-caffeoylquinic acids $(3,4 \mathrm{DC}$, $3,5 \mathrm{DC} \& 4,5 \mathrm{DC})$ in plant samples. Few studies reported on analysis of caffeoylquinic acids in plants using LCMS methods $[10,32]$. Though LCMS methods are highly sensitive, selective and reliable results, the instrument is expensive and thus the availability is limited for routine industrial application, and the procedures are laborious, complicated and costly [10, 19, 24, 32-34]. Methods using HPLC/DAD or HPLC/UV were also reported but involved complex gradient system with long run time thus may be unfavorable for routine analysis $[2,11$, 31]. In contrast, the current method employs sensitive UV detection, simple isocratic elution system with short run time for quantification of caffeoylquinic acids in G. procumbens. This method can be further extended to pharmaceutical and herbal industries for routine analysis of plants or herbal products containing the analyzed caffeoylquinic acids. 


\section{CONCLUSION}

A simple and sensitive HPLC-UV method was developed by exploiting the benefits of phenyl-hexyl column for the simultaneous determination of mono- and di-caffeoylquinic acids in G. procumbens plant samples. The developed method was validated and successfully applied for the determination of caffeoylquinic acids in various plant samples and extracts of G. procumbens. The compounds, CA; $3,4 \mathrm{DC} ; 3,5 \mathrm{Dc}$ and $4,5 \mathrm{DC}$ were present, but 1,3DC and $1,5 \mathrm{DC}$ were absent in G. procumbens samples. Leaves contained higher amount of the four compounds compared to stems. Among the compounds, 3,5DC was found to be the major caffeoylquinic acid in almost all G. procumbens samples. The method has wide application since caffeoylquininc acids are found in many plants and can be used for routine quality control and analysis of plants or herbal products containing the analyzed caffeoylquinic acids.

\section{ACKNOWLEDGMENTS}

The authors wish to express their valuable thanks to Universiti Sains Malaysia (USM) and the Ministry of Higher Education (MoHE), Malaysia for providing financial support and research facilities to carry out this research work. This project was funded by the Exploratory Research Grant Scheme (ERGS) from the Ministry of Higher Education (MoHE), Malaysia (Grant no: 203/PFARMASI/6730121) and Research University (RU) Grant from Universiti Sains Malaysia (Grant no: 1001/PFARMASI/812123).

\section{SUPPLEMENTARY MATERIAL}

The online version of this article offers supplementary material (https://doi.org/10.1556/1326.2020.00690).

\section{REFERENCES}

1. Kupiec, T. Int. J. Pharm. Compd. 2004, 8, 223-7.

2. Chen, K.; Zhang, Y.; Yang, X.; Wang, N.; Xu, W.; Zhang, Y.; Zhang, Y. J. Chin. Pharm. Sci. 2013, 22, 521-6.

3. Inbaraj, B. S.; Lu, H.; Kao, T. H.; Chen, B. H. J. Pharm. Biomed. Anal. 2010, 51, 549-56.

4. Scholz, E.; Heinrich, M.; Hunkler, D. Planta. Med. 1994, 60, 360-4.

5. Basnet, P.; Matsushige, K.; Hase, K.; Kadota, S.; Namba, T. Biol. Pharm. Bull. 1996, 19, 1479-84.
6. Zhao, Y.; Zhao, J. Zhonguo Zhongyao Zazhi 2006, 31, 869-74.

7. Nakajima, Y.; Shimazawa, M.; Mishima, S.; Hara, H. Life Sci. 2007, 80, 370-7.

8. Wang, W.; Hao, P. G.; Wang, J.; Cui, N.; Zheng, C. N.; Wang, Y. X. J. Chromatogr. Sci. 2009, 47, 216-22.

9. Lin, L. Z.; Harnly, J. M. J. Agric. Food Chem. 2007, 55, 1084-96.

10. Schütz, K.; Kammerer, D.; Carle, R.; Schieber, A. J. Agric. Food Chem. 2004, 52, 4090-6.

11. Nugroho, A.; Kim, K. H.; Lee, K. R.; Alam, Md. B.; Choi, J. S.; Kim, W. B.; Park, H. J. Arch. Pharm. Res. 2009, 32, 1361-7.

12. Chen, F.; Long, X.; Liu, Z.; Shao, H.; Liu, L. Sci. World J. 2014, $1-8$.

13. Kaewseejan, N.; Siriamornpun, S. Ind. Crops. Prod. 2015, 74, 271-8.

14. Rahman, A. F. M. M.; Asad, M. Int. J. Biosci. 2013, 3, 36-43.

15. Tan, H. L.; Chan, K. G.; Pusparajah, P.; Lee, L. H.; Goh, B. H. Front. Pharmacol. 2016, 7, 1-14.

16. ICH Harmonised Tripartite Guideline, 2005.

17. Preedy, V. R. Academic Press, Oxford, UK, 2014, 90.

18. Snyder, L. R.; Dolan, J. W. J. Chromatogr. A 1996, 721, 3-14.

19. Murugaiyah, V.; Chan, K. L. J. Chromatogr. A 2007, 1154, 198-204.

20. Chen, H. J.; Inbaraj, B. S.; Chen, B. H. Int. J. Mol. Sci. 2012, 13, 260-85.

21. Charde, M. S.; Welankiwar, A. S.; Kumar, J. Int. J. Pharm. Chem. 2014, 4, 57-61.

22. Simirgiotis, M. J. Molecules 2013, 18, 2061-80.

23. Chen, J.; Mangelinckx, S.; Ma, L.; Wang, Z.; Li, W.; Kimpe, N. D. Fitoterapia 2014, 99, 1-6.

24. Krizman, M.; Baricevic, D.; Prosek, M. J. Pharm. Biomed. Anal. 2007, 43, 481-5.

25. Grujic, N.; Lepojevic, Z.; Srdjenovic, B.; Vladic, J.; Sudji, J. Molecules 2012, 17, 2518-28.

26. Delaney, J. S. Drug Discov. Today 2005, 10, 289-95.

27. Mota, F. L.; Queimada, A. J.; Pinho, S. P.; Macedo, E. A. Ind. Eng. Chem. Res. 2008, 47, 5182-9.

28. Kroll, J.; Rawel, H. M.; Rohn, S. Food Sci. Technol. Res. 2003, 9, 205-18.

29. Teoh, W. Y.; Tan, H. P.; Ling, S. K.; Wahab, N. A.; Sim, K. S. Nat. Prod. Res. 2016, 30, 448-51.

30. Siriwatanametanon, N.; Heinrich, M. Nat. Pro. Comm. 2011, 6, 627-30.

31. Kohno, Y.; Fujita, K. Japan Soc. Anal. Chem. 2016, 65, 331-4.

32. Plazonić, A.; Bucar, F.; Maleš, Ž.; Mornar, A.; Nigović, B.; Kujundžić, N. Molecules 2009, 14, 2466-90.

33. Clifford, M. N.; Knight, S.; Kuhnert, N. J. Agric. Food Chem. 2005, 53, 3821-32.

34. Sun, Y.; Xu, L.; Wang, Q.; He, S.; Huang, H.; Zhang, W.; Li, G.; Feng, Y.; Luo, X. J. Chromatogr. B 2012, 903, 177-81. 